\title{
Effects of maternal mortality on gross domestic product (GDP) in the WHO African region*
}

\author{
Joses M. Kirigia $^{1 *}$, Doyin Oluwole ${ }^{1}$, Germano M. Mwabu ${ }^{2}$, Doris Gatwiri ${ }^{3}$, Lenity H. Kainyu ${ }^{4}$ \\ 1. World Health Organization, Regional Office for Africa, Brazzaville, Congo; 2. Department of \\ Economics, University of Nairobi, Nairobi, Kenya; 3.School of Public Health, University of New \\ South Wales, Australia; 4. School of Public Health, Kenyatta University, Kenya \\ *Author for Correspondence: Health Financing \& Social Protection Unit, World Health \\ Organization, \\ Regional Office for Africa, P.O. Box 06, Brazzaville, Congo. Tel: +47-241-39342. E-mail : \\ kirigiaj@afro.who.int
}

\begin{abstract}
SUMMARY
WHO African region has got the highest maternal mortality rate compared to the other five regions. Maternal mortality is hypothesized to have significantly negative effect on the gross domestic product (GDP). The objective of the current study was to estimate the loss in GDP attributable to maternal mortality in the WHO African Region. The burden of maternal mortality on GDP was estimated using a doublelog econometric model. The analysis is based on cross-sectional data for 45 of the 46 Member States in the WHO African Region. Data were obtained from UNDP and the World Bank publications. All the explanatory variables included in the doublelog model were found to have statistically significant effect on per capita gross domestic product (GDP) at 5\% level in a t-distribution test. The coefficients for land (D), capital (K), educational enrolment (EN) and exports (X) had a positive sign; while labor $(L)$, imports $(M)$ and maternal mortality rate (MMR) were found to impact negatively on GDP. Maternal mortality of a single person was found to reduce per capita GDP by US\$ 0.36 per year. The study has demonstrated that maternal mortality has a statistically significant negative effect on GDP. Thus, as policy-makers strive to increase GDP through land reform programs, capital investments, export promotion and increase in educational enrolment, they should always remember that investments in maternal mortalityreducing interventions promises significant economic returns.
\end{abstract}

[Afr J Health Sci. 2006; 13:86-95]

*Published online before print

\section{Introduction}

"The effects of poor health go far beyond physical pain and suffering. Learning is compromised, returns to human capital diminish, and environments for entrepreneurial and productive activities are constrained. It comes as little surprise that no country (in the Region) has attained a high level of economic development with a population crippled by high infant and maternal mortality, pervasive illness of its work force, and low life expectancy [1]. World Health Organization (WHO) estimated that 493,000 women died in 1998 of complications of pregnancy and delivery. About

forty percent $(194,000)$ of those deaths occurred in the WHO African Region. $24.1 \%$ deaths were attributed to haemorrhage, $15.9 \%$ to sepsis, $12.3 \%$ to hypertensive disorders of pregnancy, $8.2 \%$ to obstructed labour, $13.3 \%$ to abortion, and $26.2 \%$ to other maternal conditions [2]. The maternal mortality rate (MMR), the number of women who die during pregnancy and childbirth per 100000 live births, in the African Region is the highest in the world. It averages 940 deaths per 100,000 live births, with disparities among countries and between urban and rural areas in the same countries [2]. The main risk factors for 


\section{RESEARCH ARTICLE}

maternal mortality include illiteracy, poverty, poor nutrition, low weight prior to pregnancy, minimal weight gain during pregnancy, first pregnancy or higher than fourth pregnancy (excessive fertility), maternal age younger than twenty or older than thirty-four years, poor outcome of prior pregnancies, infections (e.g. STIs and HIV/AIDS) and illnesses during pregnancy (e.g. anaemia, cancer of the cervix), female genital mutilation, unintended pregnancies and unsafe abortions, smoking, and inadequate health care during pregnancy and delivery $[3,4]$.

Accessibility of an appropriate mix of costeffective interventions aimed at reducing the following three delays can diminish significantly pregnancy-related morbidity and mortality: (i) a delay at household level in deciding to seek appropriate health care; (ii) a delay in reaching health care facility; and (iii) a delay in obtaining timely and effective care after arriving at the health care facility. The first two delays could be attributed to women's lack of access and control of resources in the household; limited access to education; lack of decision-making power; and inaccessibility to regular transport facilities (including ambulance services), especially in the rural areas where more than $80 \%$ of the women live. Those delays can be significantly ameliorated by a national Safe Motherhood programme that encompasses the following six pillars: family planning, ante-natal care; essential obstetrics care; post-natal care; postabortion care; and STD/HIV prevention [5].

The effectiveness of those pillars in attenuating maternal morbidity and mortality entails: raising the socioeconomic status of women; education for women; functional and accessible primary health care; and effective communication for behavior change. In Africa, women support families through their productive labor (cash crop labor, subsistence farming, and other remunerative work), cooking for household members, providing household members with sanitary services, nursing the sick household members (at times when even they themselves are not in good health) and educating the children. Thus, the loss of a mother through death or disability robs a household of a nurturer, provider, and de facto household head [3]. There is need to sensitize national policy-makers and international development partners to the health and economic consequences of inaccessibility to the aforementioned six pillars of Safe Motherhood Initiative. To the best of our knowledge, to date no study in Africa has attempted to estimate the burden of maternal deaths on the GDP. This study represents a limited attempt to bridge this knowledge gap. Its specific objective was to estimate, using a production function (econometric) approach, the loss in GDP attributable to maternal mortality in the WHO African Region. The study could be used in various ways. (i) To sensitize health and relevant non-health sectors (e.g. planning, finance, transport) in order to generate political and economic support for the national Safe Motherhood programmes. (ii) The international non-governmental organizations that support Safe Motherhood initiatives in Africa could use the results for advocacy among bilateral and multi-lateral donors. (iii) The econometric model estimated in this study could be used to simulate the benefits of policy interventions/measures geared at attenuating the negative effects of maternal mortality on GDP. (vi) Researchers undertaking research on economic burden of maternal mortality in future could adapt the methodology used in the current study.

\section{Methods}

\section{Conceptual Framework}

The study used Production Function (PF) conceptual framework to estimate the GDP loss attributable to maternal mortality in the Region. This approach is fairly similar to that used by Gallup and Sachs in estimating the economic burden of malaria [6]. The PF describes the transformation of factor inputs into outputs at any particular time period with a given technology (i.e., a given state of knowledge about the various methods that might be used to transform inputs into outputs). The general mathematical form of the production function is: $\mathrm{Y}=\mathrm{f}(\mathrm{L}, \mathrm{K}, \mathrm{R}, \mathrm{S}, \mathrm{v}, \gamma)$, where: $\mathrm{Y}=$ output, $\mathrm{L}=$ labour (skilled, semi-skilled and unskilled), $\mathrm{K}=$ capital (buildings, equipment and inventories), $\mathrm{R}=$ raw materials, $\mathrm{S}=$ land input (which encompasses all natural resources), $\mathrm{v}=$ returns to scale, and $\gamma=$ efficiency parameter, measuring the entrepreneurial-organizational aspects of production [7]. A PF describes what is technically feasible when the firm operates efficiently; that is when the firm uses each 


\section{RESEARCH ARTICLE}

combination of inputs as effectively as possible [8]. The gross domestic product (GDP) is one of the main national output measures. GDP is the sum of total value of consumption expenditure; total value of consumption expenditure; of consumption expenditure; total value of investment expenditure; government purchases of goods and services; and net exports (i.e. exports minus imports) of goods and services. Alternatively, it can be viewed as the total value of consumption expenditure; gross private saving (business saving + personal saving + depreciation); net tax revenues (tax revenue minus domestic transfer payments, net interest paid, and net subsidies); and total private transfer payments to foreigners [9]. Intuitively, maternal mortality can impact on the production of GDP in a number of ways.

First, maternal deaths could reduce the quantity of labour force, and hence, the number of people involved in output production. However, such an effect would occur only if the levels of unemployment and underemployment are not high. If they are, arguably, it might be easy to compensate for attrition in labour force from the pool of the unemployed or underemployed.

Second, mothers play a vital role in nursing sick household members back to their normal health status, thus, death of a mother spells the loss of a strategic household caregiver or nurse. Thus, when the mother dies, the father (or some other person) is forced to reallocate work time to provide care to the bereaved children. This constitutes a loss in economically productive time.

Third, mothers not only care for the children and spouses, but also for the elderly. This is particularly important in Africa since homes for the elderly are almost non-existent, and also it is not cultural to commit them to sanatoriums. The elderly in Africa play an important role as family and community life counsellors, arbitrators of conflicts in relationships (e.g. marriage) and transmitters of indigenous 'tacit' knowledge and values to the youth. Unfortunately, maternal mortality severs the life-line for the elderly leading in turn to their premature mortality, and hence, loss of intraand intergenerational social value hitherto added by the elderly.

Fourth, there are high funeral-related costs, which at times may force the households to sell of some of the output producing assets (e.g. land, farm machinery and equipment) to pay for funerals. In African economies characterized by low capital-labour ratios, depletion of assets spontaneously erodes household production.

Fifth, maternal mortality has an adverse effect on future human capital creation process, on the quality of future labour force, and hence, future levels of GDP. This can be attributed to a number of factors. (i) Given that mothers play a prominent role in the production of household food, their death is likely to have a negative effect on the nutritional status of the children, and hence, their physical and cognitive development. (ii) In the African communities, mothers play a critical role in nurturing, socializing and educating children; thus, when a mother dies, a teacher dies. (iii) The children of maternal mortality victims may be forced to leave school early to perform duties hitherto performed by their bereaved mothers, thus weakening their future economic prospects. (iv) There is growing epidemiological evidence that maternal deaths frequently lead to infant deaths, which in turn reduces the size of future labour force.

Sixth, premature mortality of mothers who are in active labour force may lead to a reduction in total household consumption expenditure, government tax revenues, private business and personal savings, and hence, the resources available for investment purposes.

All the above factors combined only serves to stifle growth in GDP, i.e. economic growth. Formally, the effect of maternal mortality on the gross domestic product can be expressed as follows:

$G D P=f(D, L, K, H K, E A ; O E, M M R)$ (I).

where: $f=$ function of; GDP $=$ real per capita gross domestic product, i.e. real value of annual volume of goods and services divided by population; $\mathrm{D}=$ land; $\mathrm{L}=$ Labor input (people aged 15 years and above); $\mathrm{K}=$ capital stock; HK = human capital, i.e. the skills and knowledge embodied in a person; EA = entrepreneurial ability (the ability to organize and plan production and develop new products); $\mathrm{OE}=\mathrm{a}$ vector of other factors affecting production such as openness of the economy; MMR= number of women who die during pregnancy and childbirth per 100,000 live births. 


\section{RESEARCH ARTICLE}

Equation (I) shows the effect of 'MMR' on GDP, holding the effects of D, L, K, HK, EA and $\mathrm{OE}$ constant. If maternal deaths were a burden on the economies of African countries, the 'MMR' variable coefficient would be expected to assume a negative sign. Since the effects of the explanatory variables mentioned in Equation (I) on the dependent variable (GDP) are unlikely to be linear, we shall estimate a Cobb-Douglas production function of the following form:

$G D P=a D^{\beta 1} L^{\beta 2} K^{\beta 3} H K^{\beta 4} E A^{\beta 5} O E^{\beta 6} M M R^{\beta 7} \varepsilon$ .......................................... (II).

Taking logarithms of both sides of equation (II), we obtain the following log-log (or double-log, log-linear or constant elasticity model):

$\log G D P=\log a+\beta_{1} \log D+\beta_{2} \log L+\beta_{3} \log$ $K+\beta_{4} \log H K+\beta_{5} \log E A+\beta_{6} \log O E+\beta_{7} \log$ $M M R+\varepsilon$. (III)

where: $\log$ is the natural $\log$ (i.e., $\log$ to the base $e$, where is $e$ equals 2.718); $a$ is the intercept term; $\beta$ 's are the coefficients of elasticity $(\mathrm{CoE})$, i.e. responsiveness; and $\epsilon$ is a random (stochastic) error term capturing all factors that affect gross domestic product but are not taken into account explicitly [10]. CoE is the ratio of the percentage change in quantity of output produced (GDP) to the percentage change in a specific independent (explanatory) variable, such as MMR. Mathematically, the absolute value of the CoE ranges from zero (perfectly inelastic GDP) to infinity (perfectly elastic GDP). Unitary elastic output depicts a scenario in which the percentage change in quantity of GDP is exactly equal to the percentage change in an independent variable, i.e. $\mathrm{CoE}=1$. Inelastic output refers to a situation where GDP is relatively unresponsive to a change in an independent variable, i.e. $\mathrm{CoE}>0<1$. Similarly, elastic output implies that GDP is relatively responsive to a change in an independent variable, i.e. $\mathrm{CoE}>1$. Thus, in simple terms, elasticity is a measure of the degree of responsiveness of a dependent variable (GDP in our case) to changes in an independent variable, such as MMR.

\section{Data Sources and Analysis}

The data used to estimate equation (III) were obtained from two sources. GDP per capita (GDP), capital (K), school enrolment (EN), exports $(\mathrm{X})$, imports $(\mathrm{M})$, and maternal mortality rate (MMR) from UNDP [11]; arable land per capita (D) and labor force (L) from the World Bank [12].

The raw data were entered into EXCEL spreadsheet and subsequently exported to STATA [13] for analysis. Prior to estimation of the regression equation 'III', both the dependent and independent variables were transformed into their logarithms using standard STATA commands. The dependent and independent (explanatory) variables are defined in Table 1.

Table 1: Variable Descriptions and Hypothesized Signs

\begin{tabular}{|l|l|l|}
\hline Variable & Variable Description & $\begin{array}{l}\text { Expected } \\
\text { signs }\end{array}$ \\
\hline GDP & $\begin{array}{l}\text { Per capita gross domestic product (GDP), i.e. real value of annual } \\
\text { volume of goods and services divided by population (ppp US\$). }\end{array}$ & \\
\hline D & $\begin{array}{l}\text { Hectares of arable land per capita, i.e. total arable land divided by } \\
\text { population. }\end{array}$ & + \\
\hline L & $\begin{array}{l}\text { The number of people who are currently employed and people who are } \\
\text { unemployed but seeking work, as well as first-time job seekers. }\end{array}$ & \pm \\
\hline K & $\begin{array}{l}\text { Capital stock proxied by gross domestic investment (as a percentage of } \\
\text { GDP). It consists of additions to fixed assets of the economy plus net } \\
\text { changes in inventory. }\end{array}$ & + \\
\hline EN & $\begin{array}{l}\text { Human capital proxied by combined primary, secondary and tertiary } \\
\text { gross enrolment ratio }\end{array}$ & + \\
\hline $\mathrm{X}$ & $\begin{array}{l}\text { Openness of economy proxied by exports of goods and services (as a } \\
\text { percentage of GDP) }\end{array}$ & + \\
\hline M & $\begin{array}{l}\text { Openness of economy proxied by imports of goods and services (as a } \\
\text { percentage of GDP) }\end{array}$ & - \\
\hline MMR & $\begin{array}{l}\text { Number of women who die during pregnancy and childbirth per } \\
100000 \text { live births }\end{array}$ & - \\
\hline
\end{tabular}


RESEARCH ARTICLE

Table 2: Means and Standard Deviations

\begin{tabular}{|l|l|l|}
\hline Variable & Mean & Standard Deviation \\
\hline GDP & 2149.463 & 2388.444 \\
\hline Land (D) & 0.243 & 0.154 \\
\hline Labor (L) & $5,933,333$ & $8,776,000$ \\
\hline Capital (K) & 22.053 & 13.431 \\
\hline Education (EN) & 46.732 & 19.55 \\
\hline Exports (X) & 32.713 & 21.792 \\
\hline Imports (M) & 45.993 & 30.334 \\
\hline Maternal mortality ratio (MMR) & 657.53 & 365.751 \\
\hline
\end{tabular}

\section{Results}

The means and standard deviations of the untransformed variables are presented in Table 2. GDP elasticities and slope coefficients are summarized in Table 3. The adjusted R-squared is 0.7022 , meaning that the fitted model explains about 70 per cent of variations of the dependent variable, i.e. GDP. The land (D), capital (K), education (EN) and exports (X) variables have a statistically significant (at $5 \%$ level) positive impact on GDP per capita. The coefficients for labour force (L) Imports (M) and maternal mortality (MMR) have a significant negative effect on the GDP per capita

The coefficient ' $\beta$ ' measures the elasticity of GDP with respect to a particular explanatory variable, that is, the percentage change in GDP for a given small percentage change in explanatory variable in question. For example, the land (D) elasticity of GDP is 0.102 , implying that on the average a unit percentage increase in the arable land per capita will cause 0.102 percentage increase in the per capita GDP. Since the land elasticity value of 0.102 is less than 1 in absolute terms, it can be said that the GDP per capita is land-inelastic. Since elasticity is given by the following expression

$$
\left[\left(\partial G D P / \partial I V_{i}\right) \times\left(\overline{I V}_{i} / \overline{G D P}\right)\right],
$$

We obtained the slope coefficients in column 3 of Table 3 by applying the following formula:

$$
\left[\left(\overline{G D P} / \overline{I V_{i}}\right) \times \beta\right] \text {. }
$$

Where: $I V$ is the $i^{\text {th }}$ independent (explanatory) variable; $\overline{I V}$ is the mean of $\mathrm{i}^{\text {th }}$ independent variable; $\overline{G D P}$ is the average of dependent variable, i.e. GDP; $\beta$ is the elasticity of $\log$ (IV). For instance, the slope for MMR was obtained as follows: $[(2,149.463 / 657.53) \times(-$ $0.110)]=-0.35959$. The interpretation of the slope coefficient -0.35959 is that if maternal mortality increases by one person, GDP per capita on the average decreases by US $\$ 0.35959$ per year, i.e. the burden of maternal mortality on GDP per capita.

Estimates of the amount of GDP lost, in 1997, by each Member State due to maternal deaths per 100,000 live births are provided in Table 4. Those figures were obtained by multiplying US $\$ 0.35959$ by the respective maternal mortality rate. For example, the loss sustained by Angola were estimated as follows: loss per death $\times$ MMR $=$ US $\$ 0.35959 \times 1500=$ US\$540. It is important for readers to note that this is not the total loss incurred by Angola, but the result of the number of maternal deaths per 100,000 live births.

The total annual economic loss (per country) reported in Column 3 of Table 5 were estimated using the following formula: $\left.\left.\left[\left(N_{1997}-N_{1996}\right) \div 100000\right) \times M M R\right) \times L D\right]$. Where: $\mathrm{N}_{1997}=$ national population in 1997; $\mathrm{N}_{1996}=$ national population in 1996; MMR = maternal mortality rate; and $\mathrm{LD}=$ economic loss due to one maternal death (i.e. slope of MMR). The 45 countries included in the analysis together lost a total of 136,732 deaths that translated into a total annual economic loss of US $\$ 49,224$. The latter figure were obtained using the following formula: 
RESEARCH ARTICLE

$$
\left.\left.\sum_{i=1}^{45}\left[\left(N_{1997}-N_{1996}\right) \div 100000\right) \times M M R\right) \times L D\right],
$$

where the sigma sign $\sum_{i=1}^{45}$ refers to summation of annual GDP loss from the $1^{\text {st }}$ country to the $45^{\text {th }}$ country. If the average age at death were available, it would have been possible to estimate the life time economic loss (LTEL) as follows:

$$
\left.\left.L T E L=\left[\left(A G E_{R}-A G E_{D}\right) \times M D_{t}\right) \times L D\right)\right] ;
$$

where: $A G E_{R}$ is the average retirement age (which may vary from country to country), $A G E_{D}$ is the average age at maternal death, $M D_{t}$ is the total number of maternal deaths in year $t$, and $L D$ is as defined earlier. For example, if were to assume that $\mathrm{AGE}_{\mathrm{D}}=25$ years, $\mathrm{AGE}_{\mathrm{R}}=55$ years, $\mathrm{MD}_{\mathrm{t}}=136,732$, and LD $=\mathrm{US} \$ 0.36$, the grand total lifetime economic loss for the Region would $[(55-25) \times 136732) \times 0.36)]=U S \$ 1476706$.

Table 3: Effects of Various Explanatory Variables on GDP Per Capita

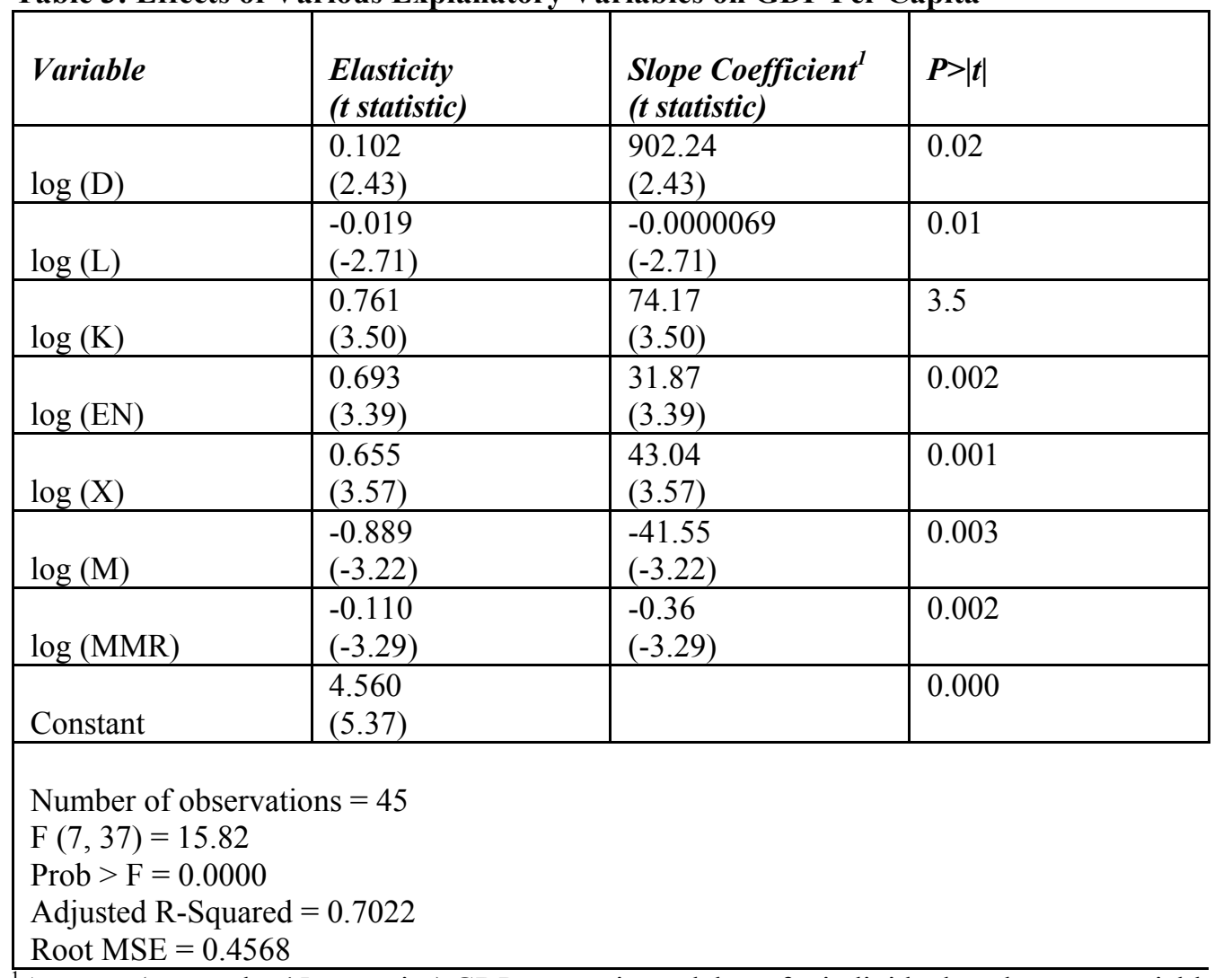

${ }^{1}$ Average (across the 45 countries) GDP per capita and those for individual explanatory variables are used in estimating the slope coefficients.

\section{Discussion}

\section{Key findings}

The main findings of this study are that: (i) maternal mortality have a statistically significant negative effect on the GDP per capita; (ii) the maternal mortality elasticity of GDP was -0.110 implying that on the average a unit percentage increase in the MMR resulted in a 0.11

percentage decrease in the GDP per capita; (iii) a unit increase in maternal mortality was found to decrease GDP per capita by US $\$ 0.35959$ per year; iv) maternal mortality results in an annual loss in GDP of US\$ US $\$ 49,224$ per year in the African region; (v) the undiscounted lifetime 
RESEARCH ARTICLE

loss in GDP due to 136,732 maternal deaths was estimated at US\$1,476,706. Although such a loss is a gross underestimate of maternal mortality, it is nevertheless a substantive loss in a region where at least $50 \%$ of the population lives below the international poverty line of US\$1 per day. A recent study of the impact of disasters mortality on GDP in the WHO African Region found that: a single natural or technological disaster-related death reduces GDP per capita by US $\$ 0.01828$ per year; disaster mortality causes an annual loss in GDP of US\$ US\$9,713 per year; the undiscounted lifetime loss in GDP due to 539,597 maternal deaths was estimated at US\$242,819 [14]. Thus, in comparative terms, the loss in GDP attributable to maternal mortality is far much higher than that resulting from disaster deaths.

Table 4: GDP Loss Attributable to Maternal Mortality Rate Per 100,000 Live Births

\begin{tabular}{|c|c|c|}
\hline Countries & MMR per 100000 live births & Economic Loss (US\$)* \\
\hline Algeria & 140 & 50.4 \\
\hline Angola & 1500 & 540 \\
\hline Benin & 500 & 180 \\
\hline Botswana & 250 & 0 \\
\hline Burkina Faso & 930 & 334.8 \\
\hline Burundi & 1300 & 468 \\
\hline Cameroon & 550 & 198 \\
\hline Cape - Verde & 55 & 19.8 \\
\hline Central African (Rep.) & 700 & 252 \\
\hline Chad & 840 & 302.4 \\
\hline Comoros & 950 & 342 \\
\hline Congo & 890 & 320. \\
\hline Democratic Republic of Congo & 870 & 313.2 \\
\hline Cote D'ivoire & 810 & 291.6 \\
\hline Equatorial Guinea & 352 & 126.72 \\
\hline Eritrea & 1000 & 360 \\
\hline Ethiopia & 1400 & 504 \\
\hline Gabon & 500 & 180 \\
\hline Gambia & 1050 & 378 \\
\hline Ghana & 740 & 266.4 \\
\hline Guinea & 880 & 316.8 \\
\hline Guinea Bissau & 910 & 327.6 \\
\hline Kenya & 650 & 234 \\
\hline Lesotho & 610 & 219.6 \\
\hline Madagascar & 500 & 180 \\
\hline Malawi & 620 & 223.2 \\
\hline Mali & 580 & 208.8 \\
\hline Mauritania & 800 & 288 \\
\hline Mauritius & 110 & 39.6 \\
\hline Mozambique & 1100 & 396 \\
\hline Namibia & 220 & 79.2 \\
\hline Niger & 590 & 212.4 \\
\hline Nigeria & 1000 & 360 \\
\hline Rwanda & 1300 & 468 \\
\hline Sao Tome \& Principe & 130 & 46.8 \\
\hline Senegal & 510 & 183.6 \\
\hline \begin{tabular}{|l|} 
Sierra Leone \\
\end{tabular} & 650 & 234 \\
\hline South Africa & 230 & 82.8 \\
\hline Swaziland & 222 & 79.92 \\
\hline Tanzania & 530 & 190.8 \\
\hline Togo & 640 & 230.4 \\
\hline Uganda & 550 & 198 \\
\hline Zambia & 650 & 234 \\
\hline Zimbabwe & 280 & 100.8 \\
\hline
\end{tabular}

*This is only the loss attributable to maternal deaths per 100,000 live births 
RESEARCH ARTICLE

Table 5: Total annual economic loss due to maternal mortality

\begin{tabular}{|c|c|c|}
\hline Countries & $\begin{array}{l}\text { Number of annual maternal } \\
\text { deaths }\end{array}$ & $\begin{array}{l}\text { Total annual economic loss } \\
\text { (US\$)* }\end{array}$ \\
\hline Algeria & 1179 & 425 \\
\hline Angola & 5441 & 1959 \\
\hline Benin & 809 & 291 \\
\hline Botswana & 250 & 90 \\
\hline Burkina Faso & 2839 & 1022 \\
\hline Burundi & 2099 & 755 \\
\hline Cameroon & 2203 & 793 \\
\hline Cape - Verde & 55 & 20 \\
\hline Central African Republic & 700 & 252 \\
\hline Chad & 1588 & 572 \\
\hline Comoros & 950 & 342 \\
\hline Congo & 890 & 320 \\
\hline Democratic Republic of Congo & 14108 & 5079 \\
\hline Cote d'Ivoire & 3820 & 1375 \\
\hline Equatorial Guinea & 352 & 127 \\
\hline Eritrea & 1000 & 360 \\
\hline Ethiopia & 22547 & 8117 \\
\hline Gabon & 500 & 180 \\
\hline Gambia & 1050 & 378 \\
\hline Ghana & 4112 & 1480 \\
\hline Guinea & 1485 & 535 \\
\hline Guinea Bissau & 910 & 328 \\
\hline Kenya & 6222 & 2240 \\
\hline Lesotho & 610 & 220 \\
\hline Madagascar & 2183 & 786 \\
\hline Malawi & 1924 & 693 \\
\hline Mali & 1489 & 536 \\
\hline Mauritania & 800 & 288 \\
\hline Mauritius & 110 & 40 \\
\hline Mozambique & 5400 & 1944 \\
\hline Namibia & 220 & 79 \\
\hline Niger & 1962 & 706 \\
\hline Nigeria & 29795 & 10726 \\
\hline Rwanda & 1545 & 556 \\
\hline Sao Tome \& Principe & 130 & 47 \\
\hline Senegal & 1286 & 463 \\
\hline Sierra Leone & 650 & 234 \\
\hline South Africa & 1810 & 652 \\
\hline Swaziland & 222 & 80 \\
\hline Tanzania & 5274 & 1899 \\
\hline Togo & 816 & 294 \\
\hline Uganda & 3052 & 1099 \\
\hline Zambia & 1484 & 534 \\
\hline Zimbabwe & 860 & 310 \\
\hline TOTAL & 136732 & 49224 \\
\hline
\end{tabular}

This is annual economic loss (deaths $\mathrm{x}$ US\$0.36) and not lifetime economic loss.

\section{Limitations of the current study}

The limitations of this study include:

A: Use of a double-log or constant elasticity model specification: The double-log model employed in this study assumes that the elasticity of coefficients between dependent variable $(\ln G D P)$ and individual independent variables $(\ln I V)$ remains constant throughout, hence the alternative name, constant elasticity model. Critics may legitimately argue that there is no reason why elasticities involved should be expected to be constant. 


\section{RESEARCH ARTICLE}

B: Use of a static as opposed to a dynamic model: As mentioned earlier, mothers make a remarkable contribution in socializing and educating children, thus their death may have adverse inter-generational effects on human capital creation, and hence, future GDP production. Sadly, the GDP calculus does not capture those inter-generational contributions of mothers, although they may be of phenomenal value for sustainability of economic growth.

C: Under-estimation of the economic burden of maternal mortality: This study attempted to estimate the loss in GDP and not the total economic cost of maternal mortality. The social value of the contribution that mothers make to society is far much greater than that captured in GDP calculations. This is because the International Labor Organization's definition of labor force includes the employed (including the armed forces), the unemployed, and firsttime job seekers, but excludes full-time homemakers and other unpaid care-givers and workers in the informal sector [15]. The majority of the mothers in Africa are either fulltime homemakers and/or informal sector workers, and thus, their invaluable contribution to society is excluded from GDP calculations.

D: Infant deaths resulting from maternal deaths: A recent study conducted in Uganda revealed that $65 \%$ of babies born to mothers who die due to pregnancy-related causes would have survived had their mothers not died [16]. This constitutes a loss in quantity of future labor force that cannot easily be captured in a static analysis.

E: Unreliable data on maternal deaths: It is common knowledge that due to weak national health management information systems (especially the vital birth and death registration systems) across the Region, maternal mortality figures reported in official sources (like those used in this study) are believed to be underestimates of actual number of maternal-related deaths.

F: Omission of economic burden of maternal-related morbidity: there is evidence that for every one woman who dies of maternal complications, there are 20 to 30 women who suffer short and long-term disabilities [16].

G: Iodine deficiency during pregnancy: Iodine deficiency during pregnancy permanently reduces learning, educational performance, and retention rates among school-age children [16].

\section{Suggestions for future research}

Since the production function approach employed in this study does not capture the full range of socio-economic losses incurred by society as a result of maternal mortality, there is need for further research to estimate economic burden of maternal mortality in a sample of countries in the Africa Region, using either micro-level costing [16] or contingent willingness-to-pay [17] methods. The former approach might enable the policy-makers to capture all socioeconomic losses related to maternal deaths. In addition, there is need for economic evaluations of the various components of safe motherhood programs (e.g. prenatal care, safe delivery, essential obstetric care, perinatal and neonatal care, postnatal care) so as to guide decision-making.

\section{Conclusion}

This study has demonstrated that maternal mortality has a statistically significant negative effect on GDP. Thus, as policy-makers strive to increase GDP through land reform programs capital investments, export promotion and increase in educational enrolment, they should always remember that investments in maternal mortality-reducing interventions promises significant economic returns. The evidence provided in this study underscores the fact that maternal mortality is both an indicator and a cause of underdevelopment

\section{Acknowledgment}

This paper is dedicated to all African women for their invaluable contributions as producers, caregivers, nurturers', educators, role-models and agents of change in society. And to the millions of other women who were victims of maternal mortality, robbed of the opportunity to fully release and maximize their awesome potential. We owe profound gratitude to Jehovah El-Shaddai for His inspiration at all stages of this work. This article contains the views of the authors only and does not represent the decisions or the stated policies of either the World Health Organization, the University of Nairobi, the University of New South Wales or the Kenyatta University.

\section{References}


1. The World Bank. Better health in Africa: experience and lessons learned. Washington, DC. 1994; 240p.

2. World Health Organisation. The World Health Report 1999: making a difference. Geneva. 1999; 122p.

3. Walsh JA; Feifer CM; Measham AR and Gertler PJ. Maternal and perinatal health. In Disease control priorities in developing countries. Edited by Jamison DT, Mosley HW, Measham AR, Bobadilla JL. New York: Oxford University press. 1993; pp.363- 390.

4. Oluwole D. Road map: African Union resolves to tackle maternal mortality. WHO/AFRO Regional Reproductive Health Newsletter 2004, 2: 1-12.

5. World Health Organisation. Regional Office for Africa. The road to safe motherhood. Harare. 1998; pp.1-11.

6. Gallup JL and Sachs DJ. The economic burden of malaria. American Journal of Tropical Medicine and Hygiene 2001, 64:85-96.

7. Koutsoyiannis A. Modern microeconomics. London: Macmillan Education Ltd. 1979; $581 \mathrm{p}$.

8. Pindyck RS and Rubinfeld DL. Microeconomics. New Jersey: Prentice Hall. 1995; 699p.

9. Branson WH. Macroeconomic theory and policy. New York: Harper \& Row. 1979; $556 \mathrm{p}$.

10. Gujarati DN. Basic econometrics. New York: McGraw-Hill Book Company. 1988; 705p.

11. UNDP. Human Development Report 2000: human rights and human development. New York: Oxford University Press. 2000; 290p.

12. The World Bank. Entering the $21^{\text {st }}$ Century: World Development Report 1999/2000. Washington, DC. 2000; 300p.

13. Stata Corporation. STATA 7.0: programming. Texas: Stata press. 2001; $368 \mathrm{p}$.

14. Kirigia JM; Sambo LG; Aldis W and Mwabu GM. Impact of disasters mortality on gross domestic product (GDP) in the WHO African Region. BMC Emergency Medicine.2004, 4:1.http://www.biomedcentral.com/I471$227 \mathrm{X} / 4 / \mathrm{I}$
15. The World Bank. World Development Indicators. Washington, DC. 1999; 399p.

16. Academy of Educational Development. Maternal survival and health: a pathway to development in Uganda. Application of the REDUCE model in Uganda. Washington, DC. 2001.

17. Kirigia JM; Sambo LG and Kainyu LH. Willingness-to-pay for schistosomiasisrelated health outcomes in Kenya. African Journal of Health Sciences. 2000, 7: 54-66. 